Catalysis Today 21 (1994) 101-112

\title{
Characterization of HDS/HDN active sites in cluster-derived and conventionally-prepared sulfide catalysts
}

\author{
J.R. Brenner, L.T. Thompson* \\ Department of Chemical Engineering, 3026 H.H. Dow Building, 2300 Hayward, \\ University of Michigan, Ann Arbor, MI 48109-2136, USA
}

\begin{abstract}
The catalytic and sorptive properties of a series of sulfide cluster-derived catalysts were compared to those of an analogous series of conventionally-prepared sulfides. The cluster-derived and conventionally-prepared catalysts had similar hydrotreatment activities and chemisorbed similar amounts of $\mathrm{O}_{2}$ and NO. From infrared spectroscopy, it was observed that the clusters retained much of their character upon adsorption, and that the CO ligands were lost upon heating up to $350 \mathrm{~K}$. Nitric oxide chemisorbed onto the bimetallic cluster-derived catalysts was initially associated with the Co sites then shifted to the Mo sites upon heating, indicating that the promoter and Mo were in close proximity. For the conventionally-prepared materials, NO adsorption suggested that the promoted and unpromoted sites behaved independently. Nitric oxide was more strongly held to the unpromoted sites in both the cluster-derived and conventionally-prepared materials. Thiophene adsorbed onto the clusterderived and conventionally-prepared catalysts gave rise to nearly identical infrared spectra. Upon heating, the thiophene peaks disappeared and were replaced by peaks that we have attributed to a linear olefin, which is noteworthy since 1-butene was the primary product from thiophene HDS. Nitric oxide easily displaced adsorbed thiophene from the cluster-derived materials, indicating that NO and thiophene adsorbed onto the same sites.
\end{abstract}

\section{Introduction}

The promotional effect of late transition metals on early transition metal sulfide hydrotreatment catalysts has been extensively investigated [1-5]. Most commercial hydrotreatment catalysts consist of Mo or W sulfides promoted with Co or Ni. A clear understanding of hydrodesulfurization (HDS) and hydrodenitrogenation (HDN) over supported hydrotreatment catalysts remains elusive because the active

\footnotetext{
* Corresponding author.
} 
sites in conventionally-prepared materials are typically minority species. Organometallic clusters appear to be useful precursors to model heterogeneous catalysts because their uniformity makes them more amenable to characterization than conventionally-prepared catalysts. Previous thiophene HDS [6] and pyridine HDN [7] activity studies in our group have shown that catalysts derived from the sulfide clusters, $(\mathrm{MeCp})_{2} \mathrm{Mo}_{2}(\mu-\mathrm{SH})_{2}(\mu-\mathrm{S})_{2}[\mathrm{MoS}],(\mathrm{MeCp})_{2} \mathrm{Mo}_{2} \mathrm{Fe}_{2}\left(\mu_{3}-\mathrm{S}\right)_{2}(\mathrm{CO})_{8}$ $[\mathrm{MoFeS}]$, and $(\mathrm{MeCp})_{2} \mathrm{Mo}_{2} \mathrm{Co}_{2}\left(\mu_{3}-\mathrm{S}\right)_{2}\left(\mu_{4}-\mathrm{S}\right)_{2}(\mathrm{CO})_{2} \quad[\mathrm{MoCoS}]$, where $\mathrm{MeCp}=$ methylcyclopentadienyl, had activities and product distributions that were similar to $\mathrm{MoS}_{2}$ and sulfided $\mathrm{Co}-\mathrm{Mo} / \gamma-\mathrm{Al}_{2} \mathrm{O}_{3}$ catalysts. In this paper, we describe the use of infrared spectroscopy to characterize the active sites in the cluster-derived and conventionally-prepared materials.

\section{Experimental}

\subsection{Preparation}

The MoS cluster was synthesized according to procedures described by Rakowski DuBois et al. [8] and the MoCoS and MoFeS were prepared using procedures outlined by Curtis and coworkers $[9,10]$. Details concerning the dispersion of these clusters onto high surface area supports have been reported elsewhere [11]. Care was taken to minimize or eliminate air exposure of the supported clusters both during preparation and characterization.

A variety of methods have been used to prepare unpromoted and promoted supported molybdate catalysts. We compared results for the cluster-derived materials with those for catalysts made by incipient wetness and equilibrium adsorption techniques. The molybdates were supported onto $\gamma-\mathrm{Al}_{2} \mathrm{O}_{3}$ and promoted with $\mathrm{Co}$, $\mathrm{Ni}$, or $\mathrm{Fe}$ to produce loadings of $1-10 \mathrm{wt} .-\%$ total metal with a $1: 1$ atomic ratio of Mo to promoter. Ammonium heptamolybdate and $\mathrm{Co}, \mathrm{Ni}$, or Fe nitrate salts were impregnated to the point of incipient wetness either sequentially with Mo first (SIW) or simultaneously (CIW). Additional materials were prepared using the equilibrium adsorption (EA) protocol for Mo [12] followed by incipient wetness impregnation of $\mathrm{Co}, \mathrm{Ni}$, or $\mathrm{Fe}$. For future reference, the code $\mathrm{M}_{1} \mathrm{Mo} / \mathrm{A}$ will denote a sulfided material containing promoter metal $\mathrm{M}_{1}$ and Mo supported on $\gamma-\mathrm{Al}_{2} \mathrm{O}_{3}$. Unless otherwise specified, the total metal loadings of the catalysts were $1 \mathrm{wt} .-\%$ metal.

After each impregnation or adsorption step, the material was calcined in dry air at $773 \mathrm{~K}$ for 5 hours. The metal loadings were confirmed by neutron activation analysis. Finally, the calcined catalysts were sulfided in a flowing $2 \% \mathrm{H}_{2} \mathrm{~S} / \mathrm{H}_{2}$ mixture $\left(100 \mathrm{~cm}^{3} / \mathrm{min}\right)$ at $673 \mathrm{~K}$ for 4 hours and stored in a dessicator. Unsupported $\mathrm{MoS}_{2}$, Crosfield 477 (2-5\% CoO, 12-16\% $\mathrm{MoO}_{3}$ ), and Crosfield 504 (2-5\% NiO, $12-16 \% \mathrm{MoO}_{3}$ ) catalysts were also examined. The Crosfield catalysts were sulfided in $2 \% \mathrm{H}_{2} \mathrm{~S} / \mathrm{H}_{2}$ at $673 \mathrm{~K}$ for 5 hours.

\subsection{Volumetric chemisorption}

We normalized the activities by volumetric chemisorption in order to make rough comparisons between the cluster-derived and conventionally-prepared catalysts. It 
has been reported that oxygen and nitric oxide chemisorb on both promoted and unpromoted sites in late transition metal promoted Mo sulfides [13-19]. Thus, the chemisorption uptake-based activities should be viewed as an average activity for the promoted Mo sulfide catalysts and a lower limit of the intrinsic activity of the promoted sites.

Oxygen uptake experiments were carried out at the dry ice/acetone temperature (195 K) using a Quantasorb sorption analyzer. The pretreatment protocol consisted of purging the catalyst bed with $\mathrm{He}$, followed by reduction in $\mathrm{H}_{2}$ at $673 \mathrm{~K}$ for at least 4 hours, then purging with He for 1 hour. Pulses of $9.98 \% \mathrm{O}_{2} / \mathrm{He}$ were dosed over the catalyst until the eluted peak area was constant for at least three consecutive injections. No significant differences were observed between the initial chemisorption measurement and one taken after rereduction. Nitric oxide $(99.9 \%)$ chemisorption was performed on some of the catalysts using the same pretreatment protocol, and the adsorption was carried out at room temperature.

\subsection{Pyridine $H D N$ activity measurements}

The catalytic activities were measured under differential conditions (conversion $<5 \%$ ) at $573-673 \mathrm{~K}$ and atmospheric pressure using a reactant mixture containing $0.6 \%$ pyridine in $\mathrm{H}_{2}$. Reaction rates were normalized based on the Mo loading or chemisorption uptake. The cluster-derived materials were heated in He up to 673 $\mathrm{K}$ at $2 \mathrm{~K} / \mathrm{min}$, cooled to $573 \mathrm{~K}$, heated back up to $673 \mathrm{~K}$ in $\mathrm{H}_{2}$ at $2 \mathrm{~K} / \mathrm{min}$, then reduced overnight at $673 \mathrm{~K}$ prior to use. The conventionally-prepared catalysts were heated in He at $2 \mathrm{~K} / \mathrm{min}$ up to $673 \mathrm{~K}$, sulfided for 4 hours in a $2 \% \mathrm{H}_{2} \mathrm{~S} / \mathrm{H}_{2}$ mixture at $673 \mathrm{~K}$, then reduced overnight at $673 \mathrm{~K}$. Reactants and products were separated using a $1.8 \mathrm{~m}$ Hayesep D column (Alltech) and analyzed using a HewlettPackard 5890 gas chromatograph. Peak areas and retention times were determined using a SpectraPhysics integrator and calibrated using standard alkane and alkene gas mixtures (Scott, $\pm 2 \%$ ).

\subsection{Infrared spectroscopy}

Materials for infrared spectroscopic characterization were prepared inside a nitrogen-filled glovebox. The cluster of interest was dissolved in dichloromethane and then pipetted onto wafers of $\gamma-\mathrm{Al}_{2} \mathrm{O}_{3}\left(10 \mathrm{mg} / \mathrm{cm}^{2}\right)$, which had been calcined at $773 \mathrm{~K}$, so as to produce a catalyst with a total metal loading of $1 \mathrm{wt} . \%$. The clusterderived materials were then inserted into an in situ cell also located inside the glovebox, and spectra were collected without exposure to ambient conditions. Pretreatment of the cluster-derived catalysts consisted of heating the materials to $673 \mathrm{~K}$ at $2 \mathrm{~K} / \mathrm{min}$ in $\mathrm{He}$ and holding at that temperature for 4 hours. After cooling and spectral collection, the wafers were heated in He back up to $673 \mathrm{~K}$ and reduced in $\mathrm{H}_{2}$ at $673 \mathrm{~K}$ for 4 hours. Unless otherwise noted, each treatment was followed by an hour-long He purge at $673 \mathrm{~K}$. For comparison, pressed wafers of blank $\gamma$ $\mathrm{Al}_{2} \mathrm{O}_{3}$ and alumina-supported catalysts prepared via the CIW, SIW, or EA-IW 
methods with the same total metal loading and atomic ratio were also examined after a similar treatment.

Following reduction in $\mathrm{H}_{2}$ and a He purge at $673 \mathrm{~K}$, nitric oxide was adsorbed onto the cluster-derived materials at room temperature (RT). Spectra were collected after purging the catalysts in $\mathrm{He}$ at $\mathrm{RT}$ for one hour so as to remove any physisorbed species. Nitric oxide desorption experiments consisted of heating the wafers at $2 \mathrm{~K} / \mathrm{min}$ up to a given temperature, holding at that temperature for one hour, cooling to RT, then collecting a spectrum.

The amount of pyridine or thiophene adsorbed onto the cluster-derived ensembles and not the alumina at temperatures lower than $673 \mathrm{~K}$ was insufficient to be detected by infrared spectroscopy. Therefore, the adsorption was carried out at elevated temperatures. The treatments prior to the adsorption measurement consisted of heating the reduced catalyst wafers in He up to $673 \mathrm{~K}$, exposing the wafers to a $0.6 \%$ pyridine or $2.7 \%$ thiophene in He mixture for 4 hours at $673 \mathrm{~K}$, cooling in the flowing adsorbate to room temperature, and then purging in He for 1 hour.

\section{Results and discussion}

\subsection{Volumetric chemisorption}

Neither $\mathrm{O}_{2}$ nor $\mathrm{NO}$ adsorbed onto the blank $\gamma-\mathrm{Al}_{2} \mathrm{O}_{3}$. Oxygen and NO chemisorptive uptakes on the bimetallic cluster-derived catalysts (MoCoS/A and MoFeS/A) were within experimental error $( \pm 15 \%)$ of each other. The oxygen uptakes for materials which had been used for HDN were typically 5-10\% lower than those for materials which had not been used, but this was also within the error of the measurements. Table 1 summarizes the chemisorption results. Notice that the uptakes on the cluster-derived materials were similar to those on the conventionally-prepared materials. In fact, with the exception of the catalysts prepared by the coimpregnation (CIW) method, the $\mathrm{O} / \mathrm{Mo}$ ratio was similar for all the catalysts. The fact that the CIW-prepared, Fe- and Co-containing materials adsorbed less oxygen than the others may be a consequence of interactions of $\mathrm{Mo}$ and $\mathrm{Fe}$ or $\mathrm{Co}$ in the impregnating solution. When we prepared impregnating solutions for the 5

Table 1

Oxygen chemisorption at $195 \mathrm{~K}$

\begin{tabular}{llllll}
\hline \multirow{2}{*}{$\begin{array}{l}\text { Total metal } \\
\text { (wt.-\%) }\end{array}$} & Preparation & \multicolumn{2}{l}{ Moles adsorbed oxygen per mole molybdenum } \\
\cline { 5 - 6 } & & Mo/A & Fe-Mo/A & Co-Mo/A & Ni-Mo/A \\
\hline 1 & CLUSTER & 0.14 & 0.10 & 0.11 & 0.14 \\
1 & CIW & 0.13 & 0.05 & 0.03 & 0.19 \\
1 & SIW & 0.13 & 0.13 & 0.08 & 0.21 \\
1 & EA-IW & 0.09 & 0.23 & 0.12 & 0.07 \\
10 & CIW & 0.07 & $\mathrm{a}$ & 0.05 & 0.08 \\
10 & SIW & 0.07 & $\mathrm{a}$ & 0.09 & 0.04 \\
10 & EA-IW & 0.11 & $\mathrm{a}$ & 0.05 & \\
\hline
\end{tabular}

${ }^{a}$ Could not be prepared. 
Table 2

Oxygen chemisorption normalized pyridine HDN activity

\begin{tabular}{llllll}
\hline \multirow{2}{*}{$\begin{array}{l}\text { Total metal } \\
(\text { wt.-\%) }\end{array}$} & Preparation & \multicolumn{2}{l}{ Pyridine $\mathrm{HDN}$ activity $\left(10^{7}\right.$ moles pyridine/mole $\left.\mathrm{O}_{2} / \mathrm{s}\right)$} \\
\cline { 3 - 6 } & & Mo/A & Fe-Mo/A & Co-Mo/A & Ni-Mo/A \\
\hline 1 & & 12 & 52 & 229 & 319 \\
1 & CLUSTER & 82 & 141 & 863 & 109 \\
1 & CIW & 82 & 128 & 482 & 20 \\
1 & SIW & 82 & 25 & 54 & 16 \\
10 & EA-IW & 82 & b & 12 & 53 \\
10 & CIW & 82 & b & 26 & 35 \\
10 & SIW & 37 & b & & \\
\hline
\end{tabular}

apyridine HDN at $633 \mathrm{~K}$, oxygen chemisorption at $195 \mathrm{~K}$.

bCould not be prepared.

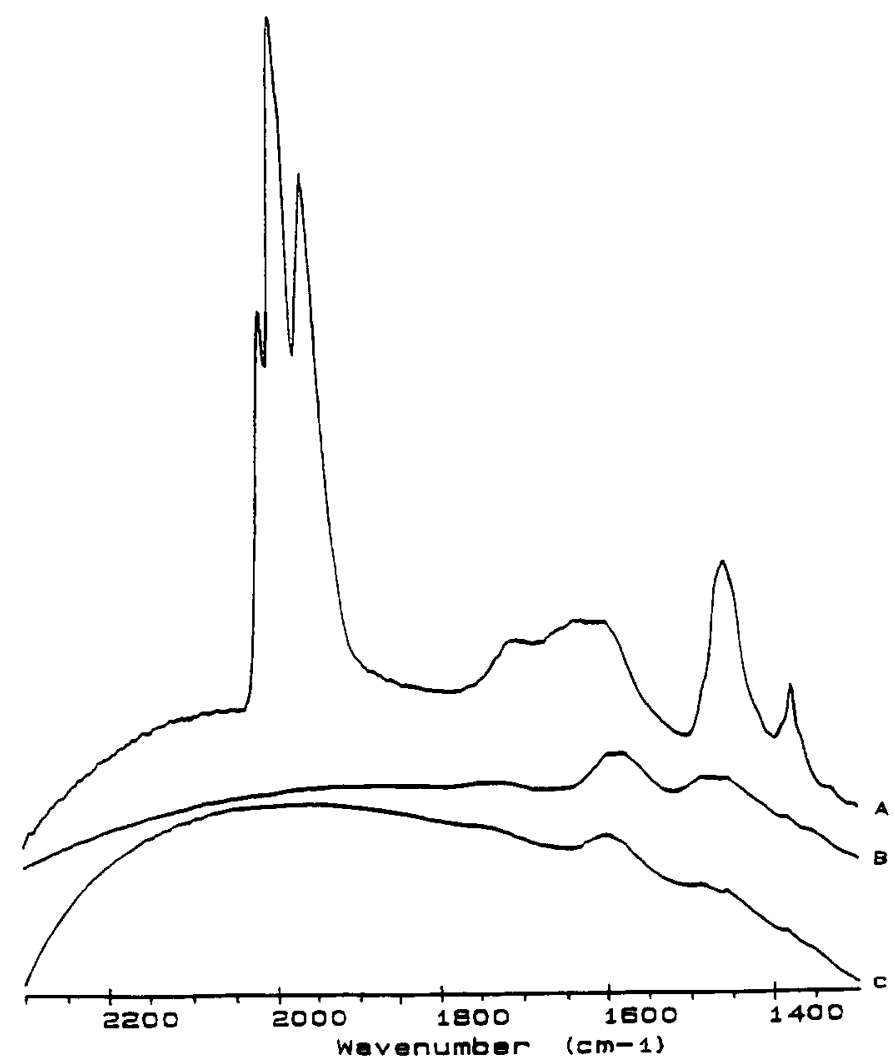

Fig. 1. Infrared spectra: (A) after adsorption of MoCoS cluster onto alumina; (B) after heating in He to $673 \mathrm{~K}$; and $(\mathrm{C})$ after reduction at $673 \mathrm{~K}$.

wt.-\% Fe-Mo/A catalyst, a gel formed within minutes. Bubbles were formed when $\mathrm{Co}$ was added to Mo-containing impregnating solutions for the high-loaded CoMo/ A catalysts. No visual evidence was observed for interactions of the Mo and $\mathrm{Ni}$ 
salts in solution. All of the $10 \mathrm{wt} .-\%$ promoted catalysts adsorbed less oxygen than the unpromoted catalysts. This was due to the formation of Co and $\mathrm{Ni}$ sulfides, which have lower chemisorptive capacities than do Mo sulfides. The amount of oxygen chemisorbed after pyridine HDN was within experimental error of that after sulfiding.

\subsection{HDN activity measurements}

Thiophene HDS [6] and pyridine HDN [7] activities and product distributions for the cluster-derived materials have been reported previously. In this paper, we report pyridine HDN activities for the conventionally-prepared catalysts and compared them with those of the cluster-derived materials (Table 2). The pyridine HDN activities of the cluster-derived materials were somewhat lower than those of the conventionally-prepared catalysts. The oxygen-uptake normalized activities for the conventionally-prepared materials decreased with increasing loading, although the per-gram activities were about the same. We believe that this was due to the formation of promoter metal sulfide domains that were less active than $\mathrm{MoS}_{2}$ or promoted- $\mathrm{MoS}_{2}$ domains. For the low-loaded catalysts, the trend with respect to the promotional effect for HDN was similar to that observed for HDS ( $\mathrm{Co}-$ $\mathrm{Mo}>\mathrm{Ni}-\mathrm{Mo}>\mathrm{Fe}-\mathrm{Mo}>\mathrm{Mo}$ ). Ho et al. reported that Ni-Mo and Fe-Mo catalysts were superior to Co-Mo for HDN at high loadings [20]. Zdrazil and coworkers did not observe a synergistic effect for Co-Mo HDN catalysts [21].

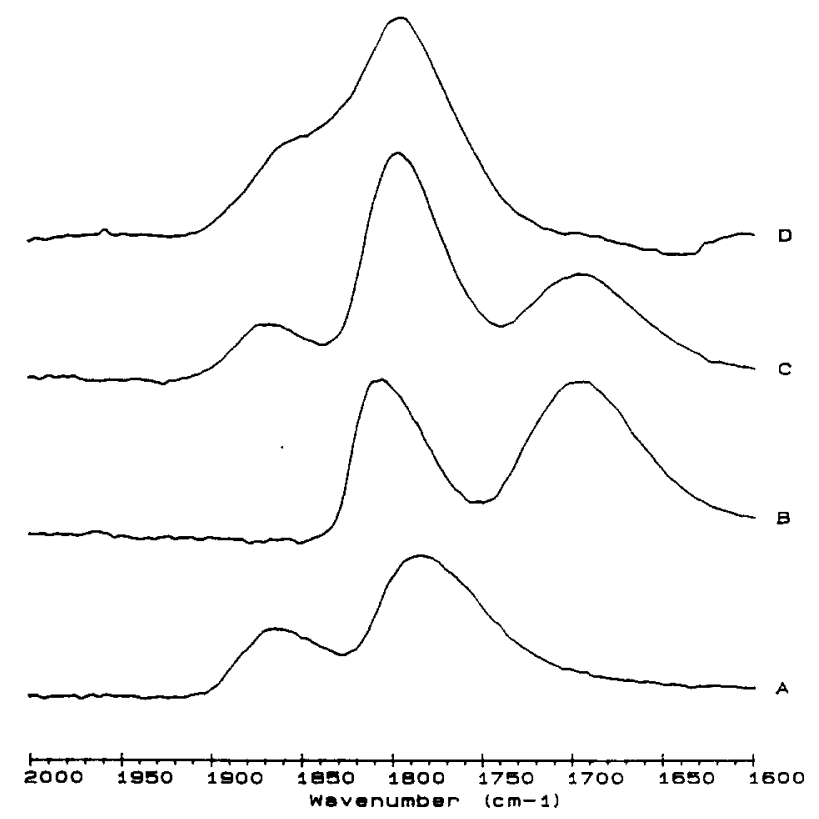

Fig. 2. Infrared spectra of NO adsorbed on (A) $1 \% \mathrm{Co} / \mathrm{A} \mathrm{IW}$, (B) $1 \% \mathrm{Mo} / \mathrm{A} \mathrm{IW}$, (C) $1 \% \mathrm{Co}-\mathrm{Mo} / \mathrm{A} \mathrm{SIW}$, and (D) $1 \% \mathrm{MoCoS} / \mathrm{A}$. 


\subsection{Infrared characterization during pretreatment of MoCoS/A}

Fig. 1A displays the spectrum of the untreated MoCoS/A catalyst. The three peaks at 2009,1989 , and $1958 \mathrm{~cm}^{-1}$ were due to terminal carbonyl stretch bands characteristic of the precursor cluster $[11,22]$. The only difference between the spectrum of the pure cluster and that of the alumina-supported cluster in this region was a slight increase in the relative intensity of the high wavenumber peak. The peaks observed between 1200 and $1800 \mathrm{~cm}^{-1}$ (Fig. 1B) were due to aluminum carbonates and bicarbonates, some of which remained after reduction (Fig. 1C). Since the clusters were the only source of $\mathrm{CO}$, the presence of carbonates suggested that the MoCoS cluster binded to the alumina by removal of carbonyl ligands from one of the Co atoms.

In situ temperature-programmed decomposition experiments revealed that the terminal carbonyl bands were lost abruptly and completely over the range of 330$360 \mathrm{~K}$. The narrow temperature range for decarbonylation suggested that the clusters produced highly uniform sites. This is consistent with our transmission electron microscopy results, which revealed a narrow size distribution for the cluster-derived scattering centers (ca. $20 \AA$ ).

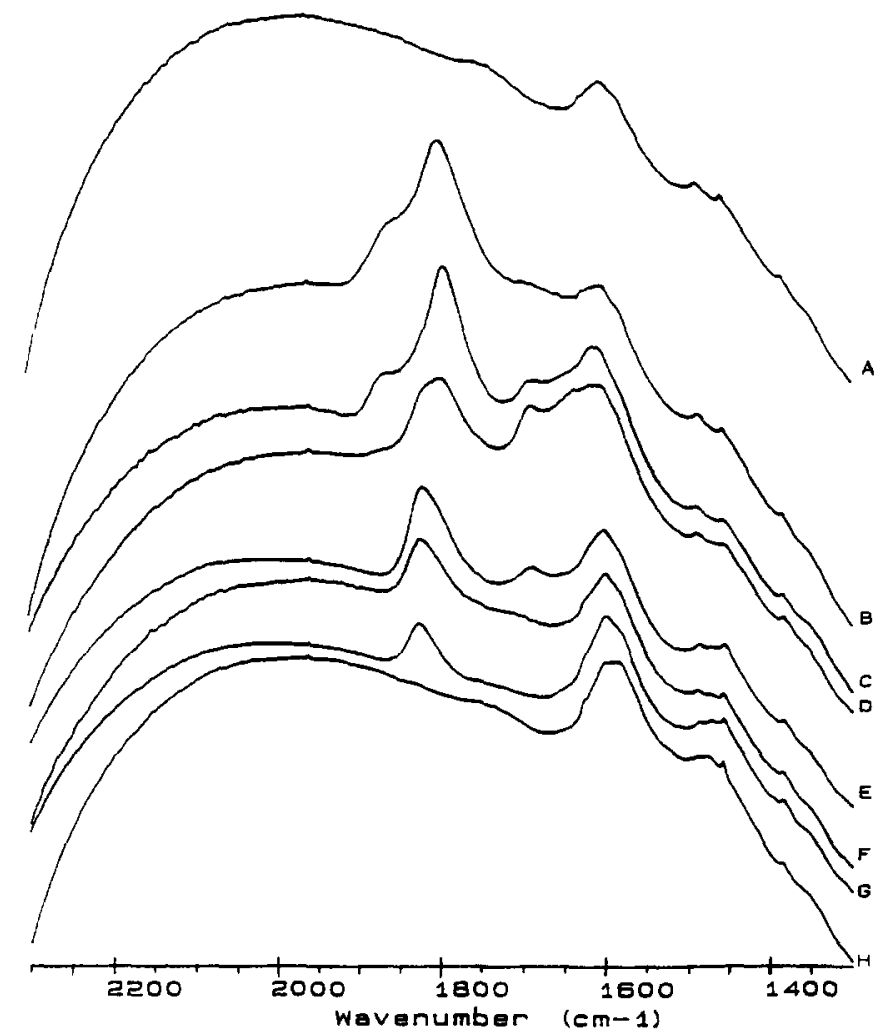

Fig. 3. Infrared spectra detailing NO adsorption/desorption onto MoCoS/A after (A) reduction and (B) NO exposure. Spectra C-H were collected at room temperature after heating the catalyst in $\mathrm{He}$ at $323,373,423,473$, 573 , and $673 \mathrm{~K}$, respectively. 


\subsection{Infrared spectroscopy of adsorbed nitric oxide}

The infrared spectra of NO adsorbed onto the $1 \mathrm{wt} . \%$ cluster-derived MoCoS/ A have been compared with those for conventionally-prepared $\mathrm{Co}-\mathrm{Mo} / \mathrm{A}, \mathrm{Mo} / \mathrm{A}$, and $\mathrm{Co} / \mathrm{A}$ sulfide catalysts (Fig. 2). The peak positions and relative intensities for NO adsorbed onto the conventionally-prepared catalysts were consistent with the wide body of literature on the subject [23-33]. For the unpromoted Mo/A catalyst, two peaks typical of NO adsorbed on Mo were observed (Fig. 2B). Nitric oxide adsorbed onto $\mathrm{Co} / \mathrm{A}$ also gave rise to two peaks, one of which overlapped the 1805 $\mathrm{cm}^{-1}$ peak for Mo (Fig. 2A). Nitric oxide adsorbed onto the three conventionallyprepared $\mathrm{Co}-\mathrm{Mo} / \mathrm{A}$ catalysts (Fig. $2 \mathrm{C}$ ) produced three peaks which were roughly but not exactly the weighted sum of the spectra of NO adsorbed onto the $\mathrm{Co}$ and Mo sulfides. For the cluster-derived MoCoS/A catalyst, NO adsorption only produced bands consistent in position with NO adsorbed onto Co (Fig. 2D). We, therefore, concluded that the character of sites on MoCoS/A was predominantly, that of the 'promoted' sites. From this point, we will refer to sites consistent with $\mathrm{NO}$ on Co as 'promoted' sites and those with $\mathrm{NO}$ on Mo as 'unpromoted' sites.

A series of spectra detailing the consequence of heating the MoCoS/A catalyst following NO adsorption are given Fig. 3. Upon heating to 323 and $373 \mathrm{~K}$ (Spectra $3 \mathrm{C}$ and $3 \mathrm{D}$ ), the peak at $1865 \mathrm{~cm}^{-1}$ due to NO on Co decreased progressively with

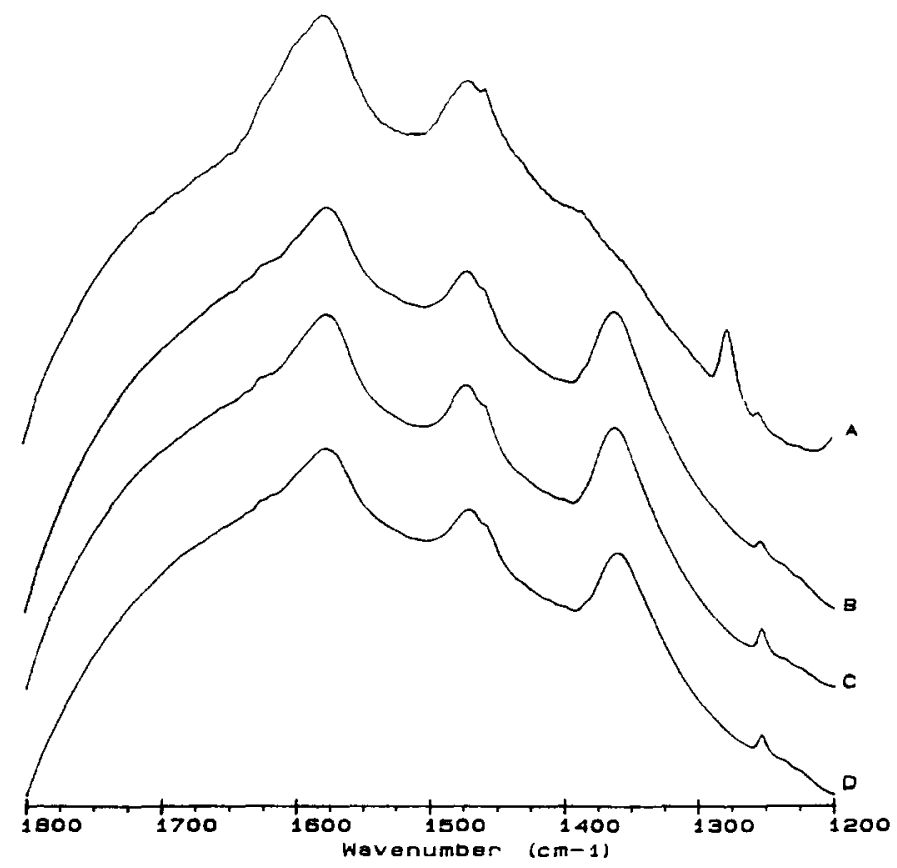

Fig. 4. No significant differences were observed in the infrared spectra of thiophene on the MoCoS/A and the conventionally-prepared $\mathrm{Co}-\mathrm{Mo} / \mathrm{A}$ catalysts. Illustrated are thiophene adsorbed on (A) $\mathrm{MoCoS} / \mathrm{A}$, (B) $\mathrm{Co}-$ Mo/A CIW, (C) Co-Mo/A SIW, and (D) Co-Mo/A EA-IW. 
respect to the peak at $1805 \mathrm{~cm}^{-1}$. Concomitantly, the intensity of the peak at 1692 $\mathrm{cm}^{-1}$, consistent with $\mathrm{NO}$ associated with unpromoted sites, increased. This result was reproduced several times. Therefore, we concluded that Mo and Co were in close proximity for the cluster-derived catalysts. This contradicts EXAFS data which suggested no Mo-Co interaction after the material had been heated above $400 \mathrm{~K}$ during the initial pretreatment [22].

The desorption behavior revealed no evidence for an interaction between the NO on promoted and unpromoted sites on the conventionally-prepared $\mathrm{Co}-\mathrm{Mo} / \mathrm{A}$ materials. However, for both the cluster-derived and conventionally-prepared catalysts, the NO desorption temperatures were $373 \mathrm{~K}$ and $673 \mathrm{~K}$ for the promoted and unpromoted sites, respectively. Rosen et al. suggested that NO adsorbs effectively as a dimer [34]. Our results were in agreement with this.

Nitric oxide could not be readsorbed onto the cluster-derived materials without reduction. After reduction, however, the materials readsorbed NO. This suggested that NO dissociated on heating, leaving atomic nitrogen or oxygen behind. Presumably, the nitrogen and oxygen were removed during reduction.

\subsection{Infrared spectroscopy of adsorbed pyridine and thiophene}

The spectra of pyridine adsorbed onto the cluster-derived catalysts and blank $\gamma-$ $\mathrm{Al}_{2} \mathrm{O}_{3}$ were indistinguishable. This suggested that most, if not all, of the pyridine adsorbed onto the $\gamma-\mathrm{Al}_{2} \mathrm{O}_{3}$ surface; therefore, pyridine adsorption results will not be discussed further.

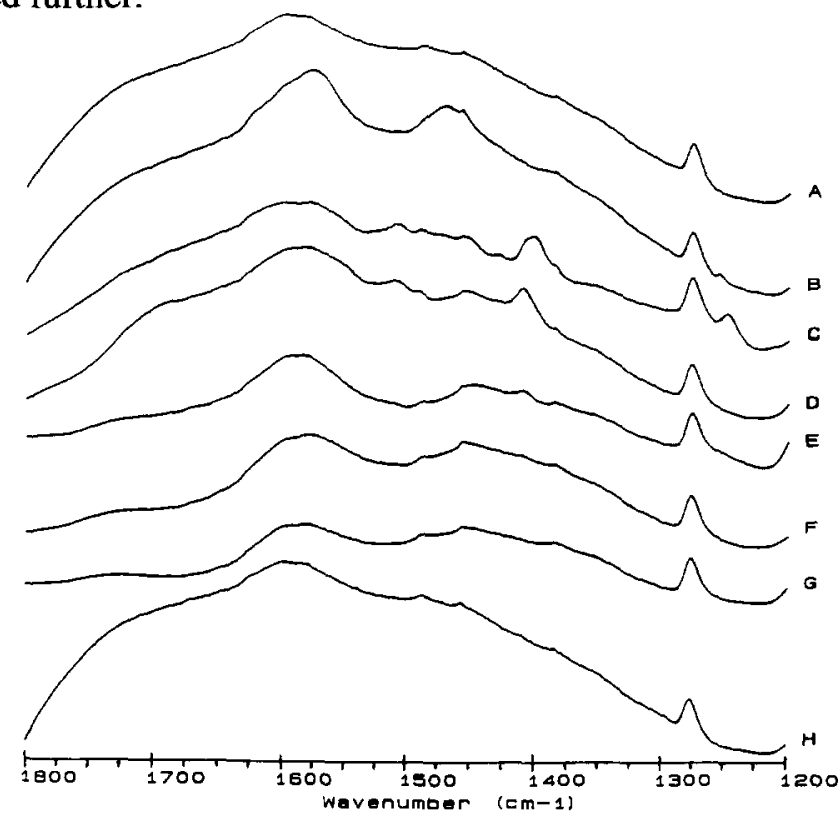

Fig. 5. Infrared spectra detailing adsorption/desorption of thiophene onto MoCoS/A following (A) reduction at $673 \mathrm{~K}$, and (B) exposure to thiophene. Spectra $\mathrm{C}-\mathrm{G}$ were collected at room temperature after heating the catalyst in $\mathrm{He}$ at $323,373,473,573$, and $673 \mathrm{~K}$, respectively. Spectrum $\mathrm{H}$ is of the rereduced material. 


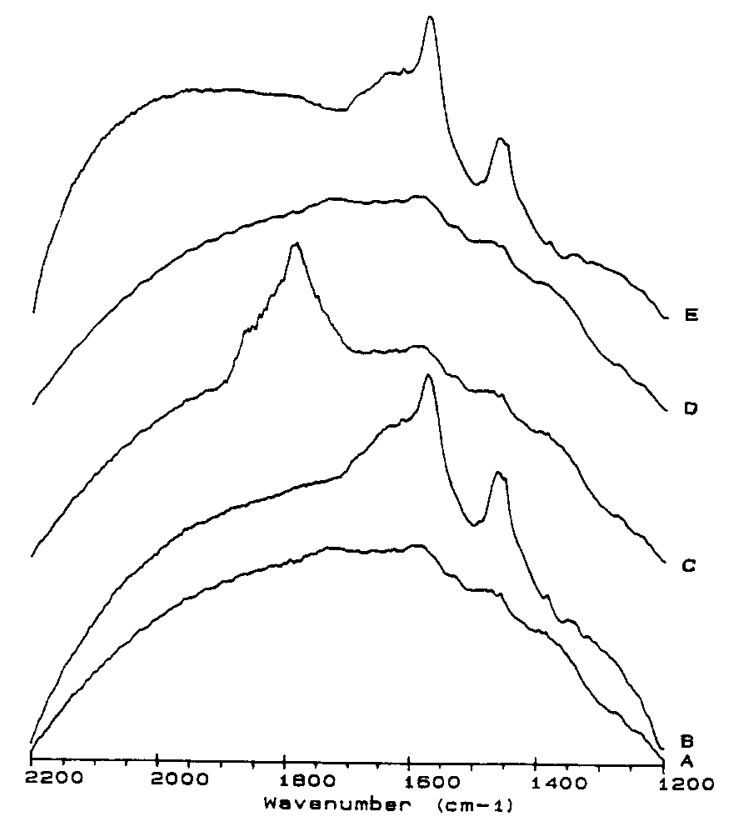

Fig. 6. Infrared spectra of the MoCoS/A catalyst following (A) reduction at $673 \mathrm{~K},(\mathrm{~B})$ exposure to thiophene, (C) exposure to NO after thiophene, (D) rereduction at $673 \mathrm{~K}$, and (E) exposure again to thiophene.

The character of thiophene adsorbed onto the cluster-derived MoCoS/A and conventionally-prepared Co-Mo/A catalysts were strikingly similar (Fig. 4). We attributed the bands at 1576,1471 , and $1253 \mathrm{~cm}^{-1}$ to aromatic $\mathrm{C}=\mathrm{C}$ stretches from adsorbed thiophene based on a comparison of the positions with liquid-phase thiophene $\left(1592,1435-1400\right.$, and $1255-1210 \mathrm{~cm}^{-1}$, [35]) and gaseous thiophene (1601, 1461, and $1258 \mathrm{~cm}^{-1}$ ).

A series of spectra tracking the fate of thiophene adsorbed on the MoCoS/A catalyst is illustrated in Fig. 5. Heating to $323 \mathrm{~K}$ in He caused a gradual decrease in the aromatic $\mathrm{C}=\mathrm{C}$ features at 1576 and $1471 \mathrm{~cm}^{-1}$ (Fig. 5C). The weak but sharp peak observed at ca. $1253 \mathrm{~cm}^{-1}$ increased in intensity. We also observed the emergence of a broad band at $1710 \mathrm{~cm}^{-1}$, consistent with alkene $\mathrm{C}=\mathrm{C}$ bonding. The strong bands at ca. $1400 \mathrm{~cm}^{-1}$ were characteristic of an in-plane scissoring, terminal alkene $\mathrm{C}-\mathrm{H}$ bond. Weaker bands at $1451-1461 \mathrm{~cm}^{-1}$ indicative of methylene groups were also observed. All these features suggested that the thiophenic surface species was replaced by a linear olefin. This olefinic group may be a precursor to 1-butene, the most common product of thiophene HDS over both the cluster-derived [6] and conventionally-prepared materials [36]. A small, as-yet unassigned peak was also observed at $1307 \mathrm{~cm}^{-1}$. After a one hour purge in $\mathrm{He}$ at $373 \mathrm{~K}$, the peaks at 1307 and $1248 \mathrm{~cm}^{-1}$ were no longer discernable, and the peaks attributed to the linear olefin increased in intensity for all the catalysts. After the materials were heated to $473 \mathrm{~K}$ for one hour, the band at $1710 \mathrm{~cm}^{-1}$ was almost completely removed (Fig. 5E), indicating that the olefinic species had desorbed. 
Further heating in He did not significantly influence the spectra (Fig. 5F and 5G). Finally, spectra taken after reduction at $673 \mathrm{~K}$ (Fig. $5 \mathrm{H}$ ) were nearly identical to spectra prior to the thiophene exposure (Fig. 5A), indicating that the reduction sufficiently regenerated the catalysts.

It appeared that thiophene was weakly adsorbed on both the MoCoS/A and conventionally-prepared $\mathrm{CoMo} / \mathrm{A}$ catalysts and desulfurized once adsorbed. From the infrared spectra of thiophene alone, we were unable to distinguish between the promoted and unpromoted sites. However, NO easily displaced thiophene from sites in the MoCoS/A catalyst as indicated in Fig. 6. Note that the NO spectrum following thiophene displacement was similar to the NO spectrum for the freshly reduced material. This behavior was reproducible as indicated in Figs. 6D and 6E. Based on this evidence, we concluded that NO and thiophene adsorbed onto the same sites.

\section{Conclusions}

The chemisorption results suggested similar site densities for the cluster-derived and conventionally-prepared catalysts. The ratio of adsorbed $\mathrm{O}_{2}$ or $\mathrm{NO}$ to Mo was generally the same for the cluster-derived and conventionally-prepared catalysts. The only exceptions were several high-loaded catalysts prepared by coimpregnation, for which interactions occurred between Mo and the Fe or Co species in the impregnating solution.

The pyridine HDN activities of the cluster-derived materials were somewhat less than those of the conventionally-prepared catalysts. The trends with respect to the promotional effect for HDN for both the $1 \mathrm{wt} .-\%$ metal-loaded cluster-derived and conventionally-prepared materials were the same as those observed for HDS $(\mathrm{CoMo} / \mathrm{A}>\mathrm{Ni}-\mathrm{Mo} / \mathrm{A}>\mathrm{FeMo} / \mathrm{A}>\mathrm{Mo} / \mathrm{A})$. For the $10 \mathrm{wt.}$ \% metal loadings, however, the HDN activity decreased upon the addition of $\mathrm{Co}$ and $\mathrm{Ni}$, which we believe to be due to the formation of bulk promoter sulfides.

Infrared spectroscopy indicated that NO adsorbed predominantly onto Co sites in the MoCoS cluster-derived catalysts. As the materials were heated, the intensity of the peak attributed to NO on Co sites decreased concomitantly with the appearance of a band consistent with NO on Mo, indicating that in these catalysts, the chemistries of the promoted and unpromoted sites were connected. One would also deduce that Mo and Co were in close proximity. In contrast, NO desorbed from the Co and Mo sites independently for the conventionally-prepared materials.

Thiophene adsorbed onto the cluster-derived and conventionally-prepared CoMo catalysts gave rise to nearly identical infrared spectra. Upon heating, the thiophene peaks were replaced by peaks that we have attributed to a linear olefin, which might be a precursor to 1-butene, the primary product from thiophene HDS. Adsorbed thiophene was easily displaced by NO at room temperature. The resulting NO spectrum was nearly identical to that of NO adsorbed on the freshly reduced catalyst. This suggested that thiophene and NO adsorbed onto the same site. 


\section{Acknowledgments}

The authors would like to thank NSF (Grant CTS-9158527) for funding this research as well as Nedra DeGraffenreid and Cecelia Duster for their assistance in this work.

\section{References}

[1] B. Delmon, Am. Chem. Soc., Div. Petr. Chem., Prepr., 22 (2) (1977) 503.

[2] V.H. DeBeer and G.C. Schuit, in B. Delmon, P. Jacobs and G. Poncelet (Editors), Preparation of Catalysts 1, (Studies in Surface Science and Catalysis, Vol. 1), Elsevier, Amsterdam, 1976, p. 343.

[3] H. Topsøe, B.S. Clausen, R. Candia, C. Wivel and S. Mørup, J. Catal., 68 (1981) 433.

[4] S. Mørup, B.S. Clausen and H. Topsøe, J. de Phys., 40 (C2) (1979) 88.

[5] B.S. Clausen, H. Topsøe, R. Candia, R. Villadsen, B. Lengeler, J. Als-Nielsen and F. Christensen, J. Phys. Chem., 85 ( 1981 ) 3868.

[6] B.T. Carvill and L.T. Thomson, Appl. Catal., 75 (1991) 249.

[7] J.R. Brenner, B.T. Carvill and L.T. Thompson, Appl. Organomet. Chem., 6 (1992) 463.

[8] M. Rakowski DuBois, M.C. VanDerveer, D.L. Dubois, R.C. Haltiwanger and W.K. Miller, J. Am. Chem. Soc., 102 (1980) 7456.

[9] M.D. Curtis and P.D. Williams, Inorg. Chem., 22 (1983) 2261.

[10] P.D. Williams, M.D. Curtis, D.N. Duffy and W.M. Butler, Organometallics, 2 (1983) 165.

[1 1] P.D. Williams, Ph.D. Dissertation, Dept. of Chemistry, University of Michigan (1985).

[12] L. Wang and W.K. Hall, J. Catal., 77 (1982) 232.

[13] W. Zmierczak, G. Muralidhar and F.E. Massoth, J. Catal., 77 (1982) 432.

[14] T.A. Bodrero and C.H. Bartholomew, J. Catal., 84 (1983) 145.

[15] B.M. Reddy and V.S. Subrahmanyam, Appl. Catal., 27 (1986) 1.

[16] S.J. Tauster, T.A. Pecoraro and R.R. Chianelli, J. Catal., 63 (1980) 515.

[17] H.-C. Liu and S.W. Weller, J. Catal., 61 (1980) 282.

[18] Z. Shuxian, W.K. Hall, G. Ertl and H. Knözinger, J. Catal., 100 (1986) 167.

[19] K. Segawa and W.S. Millman, J. Catal., 101 (1986) 430.

[20] T.C. Ho, A.J. Jacobson, R.R. Chianelli and C.R.F. Lund, J. Catal., 138 (1992) 351.

[21] J. Sobczak, Z. Vit and M. Zdrazil, Appl. Catal., 45 (1988) L23.

[22] M.D. Curtis, Appl. Organomet. Chem., 6 (1992) 429.

[23] K. Segawa and W.K. Hall, J. Catal., 77 (1982) 221.

[24] J. Valyon and W.K. Hall, J. Catal., 84 (1983) 216.

[25] K. Segawa and W.S. Millman, J. Catal., 101 (1986) 223.

[26] N.-Y. Topsøe and H. Topsøe, J. Catal., 75 (1982) 354.

[27] N.-Y. Topsøe and H. Topsøe, J. Catal., 77 (1982) 293.

[28] N.-Y. Topsøe and H. Topsøe, J. Catal., 84 (1983) 386.

[29] N.-Y. Topsøe and H. Topsøe, J. Electron Spectros. Relat. Phenom., 39 (1986) 11.

[30] A. Maezawa, M. Kitamura, Y. Okamoto and T. Imanaka, Bull. Chem. Soc. Jpn., 61 (1988) 2295.

[31] H.C. Yao and W.G. Rothschild, in: H.F. Barry and P.C.H. Mitchell (Editors), Proc. 4th International Conf. on The Chemistry and Uses of Molybdenum, Climax Molybdenum Company, Ann Arbor, MI, 1982, p. 31.

[32] J.B. Peri, J. Phys. Chem., 86 (1982) 1615.

[33] J.B. Peri, Am. Chem. Soc., Div. Pet. Chem., 23 (1978) 1281.

[34] R.P. Rosen, K. Segawa, W.S. Millman and W.K. Hall, J. Catal., 90 (1984) 368.

[35] L.J. Bellamy, The Infrared Spectra of Complex Molecules, Wiley, New York, 1975, pp. 317-318.

[36] S. Kolboe and C.H. Amberg, Can. J. Chem., 44 (1966) 2623. 